\title{
Vascular Occlusion Techniques during Liver Resection
}

\author{
Thomas M. van Gulik Wilmar de Graaf Sander Dinant Olivier R.C. Busch \\ Dirk J. Gouma \\ Department of Surgery, Academic Medical Center, Amsterdam, The Netherlands
}

\author{
Key Words \\ Extended liver resection - Ischemic tolerance of the liver • \\ Liver resection - Low central venous pressure - Pringle, \\ continuous or intermittent $\cdot$ Pringle maneuver $\cdot$ Total \\ hepatic vascular exclusion - Vascular occlusion, \\ hemihepatic or segmental $\cdot$ Vascular occlusion techniques
}

\begin{abstract}
Control of bleeding from the transected liver basically consists of vascular inflow occlusion and control of hepatic venous backflow from the caval vein. Central venous pressure determines the pressure in the hepatic veins and is an extremely important factor in controlling blood loss through venous backflow. Vascular inflow occlusion (Pringle maneuver) involves clamping of the portal vein and the hepatic artery in the hepatic pedicle and gives rise to postischemic, reperfusion injury. Several strategies have been devised to reduce reperfusion injury (pharmacological interventions) or to increase ischemic tolerance of the liver (ischemic preconditioning). Intermittent clamping is recommended in complex liver resections or in patients with diseased livers. The combination of occlusion of vascular inflow and outflow of the liver results in total hepatic vascular exclusion (THVE) and is mainly used in tumors invading the caval vein. During
\end{abstract}

THVE the liver can be cooled by hypothermic perfusion allowing for extended ischemia times. Selective THVE entails clamping of the main hepatic veins in their extrahepatic course, thus preserving caval flow. Safe liver surgery requires knowledge of the regular techniques of vascular occlusion for 'on demand' use when necessitated to reduce blood loss.

Copyright $\odot 2007$ S. Karger AG, Basel

\section{Introduction}

Liver resections have become safer in the past decade, largely owing to refinements in surgical techniques, improved selection of patients for surgery and advances achieved in postoperative care. At the same time, the indications for performing more extensive liver resections have expanded and an increasing number of more complex resections are nowadays undertaken. Hence, although mortality has decreased, morbidity is still substantial, especially in patients undergoing extended liver resections or in patients with underlying parenchymal liver disease, such as cirrhosis or steatosis. Several studies have shown that the most important determinants of mortality and morbidity are the number of segments re- 
Table 1. Various vascular occlusion techniques that can be applied to reduce blood loss during liver resection

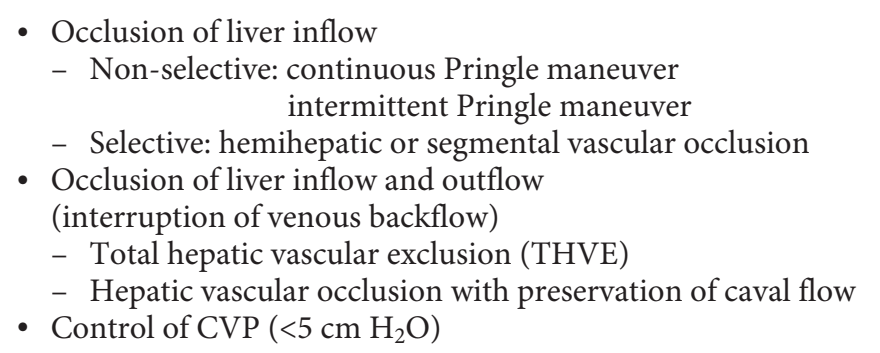

sected and the volume of operative blood loss [1]. The techniques developed to deal with blood loss during liver resection have been instrumental in reducing postoperative complications. Three key factors have greatly contributed to our ability to control blood loss. Firstly, our knowledge of surgical anatomy of the liver as laid down by Couinaud [2], who defined the division of the liver into segments, each with its own vascular supply. The intersegmental planes are relatively avascular enabling us to perform anatomical resections with minimal blood loss when respecting the segmental borders. Secondly, new methods for parenchymal dissection have emerged which allow us to transect the liver without excessive blood loss [3]. Thirdly, methods have been developed to reduce blood loss by temporarily clamping the portal vein and hepatic artery in the hepatic pedicle, with or without concomitant control of backflow from the caval vein through the hepatic veins $[4,5]$. This paper focuses on the various techniques of vascular occlusion that can be applied to reduce blood loss during liver resection as summarized in table 1 .

\section{Importance of Low Central Venous Pressure}

Several studies have emphasized the importance of avoiding elevated central venous pressure (CVP) during liver resection $[6,7]$. Increased CVP leads to higher pressure in the hepatic veins and, consequently, increased venous backflow with a higher risk of losing blood while transecting the liver. Low CVP $\left(<5 \mathrm{~cm} \mathrm{H}_{2} \mathrm{O}\right)$ is, therefore, prerequisite for performing safe liver resection, and should be observed by the surgeon in close collaboration with the anesthetic team. The anesthetist, whose main concern is adequate perfusion of vital organs, should be

Vascular Occlusion Techniques during Liver Resection aware of the crucial relation between blood loss and elevated CVP in liver surgery. In case of major bleeding, the inexperienced anesthetist will tend to fill the patient up which inevitably leads to increased bleeding, hence generating a vicious circle which is difficult to break. A continuous dialogue between surgeon and anesthetist is therefore of utmost importance during complex liver resection. The advantages should of course be balanced against the drawbacks of maintaining low CVP, such as the risk of air embolism during parenchymal transection, reduction of retrograde venous liver perfusion, insufficient left ventricular preload and inadequate end-organ perfusion.

\section{Pringle Maneuver}

The best known, time-honored method to control blood loss during parenchymal transection is clamping of the hepatic pedicle, a maneuver which is eponymously attached to the name of Dr. Pringle, a surgeon working in the Royal Infirmary in Glasgow at the end of the 19th century. He described in his landmark article in the $A n-$ nals of Surgery of 1908 [8] how he intuitively clamped the afferent vessels to the liver in an attempt to arrest major hemorrhage resulting from severe liver trauma. Although he succeeded in controlling blood loss, the 8 patients he described unfortunately all died. Pringle's report was at the time remarkable, as many surgeons were reluctant to occlude the afferent vessels to the liver in the light of animal experiments showing that inflow occlusion of the liver was lethal. Experiments had been carried out by Langenbuch, who tied the hepatoduodenal ligament in dogs and found that the animals succumbed within a short time [8]. These animals, we know now, did not die of liver ischemia but succumbed because of the intestinal congestion secondary to occlusion of the portal vein. Fortunately, humans support prolonged clamping of the portal vein much better owing to a naturally occurring, portal-systemic collateral circulation, allowing clamping of the hepatic pedicle for considerable time without mesenteric congestion. Even implantation of a liver graft is nowadays undertaken without venous-venous bypass.

\section{Dilemma in Extended Liver Resection}

Occlusion of both the portal vein and hepatic artery obviously results in total ischemia of the liver. Ischemia can be defined as 'a condition in which an organ is de- 
prived of sufficient blood supply'. It is accompanied by lack of oxygen and substrates, essential sources for cellular energy metabolism and a failure to remove endproducts of metabolism [9]. This will lead to increased lactate production and, therefore, metabolic acidosis due to anaerobic glycolysis. The lack of adenosine 5 '-triphosphate as energy substrate, which is needed for maintenance of cell homeostasis and integrity, will cause cellular dysfunction, cellular and interstitial edema and eventually massive cell death (necrosis).

When releasing the clamps after completion of parenchymal transection, blood flow to the liver is restored and the remnant liver is reperfused. Reperfusion has important benefits such as restoration of oxygen supply and removal of toxic metabolites. On the other hand, the combination of ischemia and subsequent reperfusion paradoxically enhances damage and inflammation [10, 11]. Two different phases of ischemia and reperfusion injury can be distinguished. An early phase $(<2 \mathrm{~h}$ after reperfusion) in which production of reactive oxygen species plays a dominant role and a late phase $(6-48 \mathrm{~h}$ after reperfusion), characterized by the onset of an inflammatory response. These phases lead to increased parenchymal cell death with leakage of intracellular enzymes such as aspartate aminotransferase and alanine aminotransferase, as well as increased apoptosis. The impact of liver ischemia and reperfusion injury is greatly enhanced when combined with liver resection [12]. Hence, the dilemma when performing extended liver resection is whether to clamp and prevent loss of excessive blood, but because of clamping, increase the risk of remnant liver failure by inducing ischemic damage to the liver and delaying hepatic regeneration. The latter is overruled by the serious consequences of major blood loss, while the liver tolerates ischemia better than blood loss. This supports the notion that it is better to clamp than to bleed.

\section{Strategies to Increase Ischemic Tolerance of the Liver}

Several strategies have been devised to reduce postischemic, reperfusion injury or to increase tolerance of the liver to ischemia (table 2). Many of these strategies have been investigated in animal studies, mostly in rodent models of ischemia and reperfusion injury. The major limitations of animal studies in regard with liver ischemia are a marked species difference in ischemic tolerance of the liver and the inability of the splanchnic venous
Table 2. Strategies to reduce ischemia/reperfusion injury during liver resection

- Pharmacological interventions (allopurinol, acetylcysteine, adenosine)

- Interventions in inflammatory cascade (C1 inhibitor, interleukin-10, lipopolysaccharide-blocking agents)

- Ischemic preconditioning of the liver

- Intermittent vascular inflow occlusion (intermittent Pringle maneuver)

- In situ cooling of the liver under total hepatic vascular exclusion (use of flush solutions)

system in animals to sustain portal venous occlusion [13].

Pharmacological interventions have been examined, focusing on different aspects of ischemia and reperfusion injury, such as scavenging of reactive oxygen species, decreasing apoptosis or inhibition of the inflammatory response or coagulation [14-18]. In humans however, not many options are available for treatment of the ischemia- and reperfusion-induced systemic inflammatory response syndrome. Prevention of inflammation is another possible way to diminish ischemia/reperfusion injury. The hepatoprotective effect of $\mathrm{C} 1$ inhibitor, a major inhibitor of the classical complement pathway, was shown in a model of partial liver ischemia and reperfusion in the rat [19]. Interleukin-10 is a potent anti-inflammatory cytokine, which inhibits the production of proinflammatory cytokines such as interleukin-6, as well as of chemokines released by activated monocytes, macrophages and neutrophils. The effect of interleukin-10 administration has been studied in various models of ischemia and reperfusion injury. In most of these studies, interleukin-10 appears to have an attenuating effect on organ damage caused by ischemia and reperfusion, including post-ischemic reperfusion injury of the liver [20].

Another mediator that enhances damage and inflammation after hepatic ischemia and reperfusion as well as partial liver resection is lipopolysaccharide, an endotoxin derived from Gram-negative bacteria [21-23]. Lipopolysaccharide is released by these bacteria after migrating through the intestinal mucosa into the portal circulation and lymph nodes. Bacterial translocation is increased during and after hepatic ischemia/reperfusion and resection $[12,24]$.

Ischemic preconditioning of the liver has recently been proposed as a hepatoprotective measure and consists of 
application of a brief period of ischemia (10 $\mathrm{min})$ and reperfusion $(10 \mathrm{~min})$ after which a prolonged period of the Pringle maneuver is supported by the liver [25]. In a prospective series comparing major liver resections using the Pringle maneuver lasting 30-60 min, an advantage was found of ischemic preconditioning in young patients $(<60$ years) and in patients with steatosis [26].

\section{Continuous or Intermittent Pringle}

Clamping of the hepatoduodenal ligament during partial liver resections results in temporary occlusion of the portal vein and hepatic artery. Controversy exists as to whether clamping should be applied continuously or intermittently [27]. Continuous clamping results in one prolonged period of ischemia followed by reperfusion, whereas during intermittent clamping multiple short periods of ischemia are induced, however all followed by a reperfusion episode. The issue comes down to the question if multiple short episodes of ischemia and reperfusion are more detrimental to the liver than one prolonged period of ischemia followed by final reperfusion. This question has been addressed in animal studies, mainly in rats, and in few clinical studies. In rat studies, hepatocellular damage and survival were assessed as parameters of liver injury, providing no uniform support for one of the two methods [28-31]. Studies in rats using cirrhotic liver models or applying prolonged periods of ischemia showed a benefit from intermittent hepatic vascular clamping $[30,32]$. In a clinically relevant pig model of hepatic pedicle clamping in combination with partial liver resection, we have compared continuous and intermittent clamping using parameters of microvascular and parenchymal damage in this model $[33,34]$. We could demonstrate a reduction of postischemic reperfusion injury after prolonged (120 min) intermittent vascular inflow occlusion in hemihepatectomized pigs, compared to continuous occlusion. When vascular inflow occlusion, however, was shorter than $90 \mathrm{~min}$, continuous clamping resulted in less microcirculatory and hepatocellular injury. Translating the results of these experiments to the clinical situation, intermittent clamping probably is beneficial when in complex liver resections clamping time is expected to exceed the period of $60 \mathrm{~min}$. In straightforward cases of liver resection in which parenchymal transection can be completed within $30 \mathrm{~min}$, little advantage of intermittent clamping is to be expected.
In the clinical situation, intermittent clamping entails periods of 15-30 min of ischemia, followed by 5-15 $\mathrm{min}$ of reperfusion [35]. Total ischemia time is shortened at the costs of increased periods of reperfusion and bleeding, as well as increased time for parenchymal transection of the liver. Intermittent clamping has the practical advantage that during each cycle of reperfusion, hemostasis of the cut surface of the liver can be checked in a step-by-step fashion. Belghiti et al. [27] compared 42 patients who underwent continuous clamping and 44 patients who underwent intermittent clamping (15 min clamping and 5 min of unclamping) in a randomized study. Intraoperative blood loss was significantly higher in the intermittent group, whereas in the continuous group postoperative serum bilirubin and liver enzymes were significantly higher in patients with abnormal liver parenchyma (steatosis and cirrhosis). In all, intermittent clamping permits increase of safe ischemic time up to 322 min in normal livers and $204 \mathrm{~min}$ in impaired livers and is the recommended method especially in patients undergoing complex liver resections and patients with diseased livers [36, 37].

\section{Hemihepatic or Segmental Vascular Occlusion}

Instead of interrupting all vascular inflow to the liver, only the vascular supply to hemi-liver or one or two segments may be occluded. The half-Pringle maneuver is useful in dealing with peripherally located tumors, when a bi-segmentectomy is performed as in a segment $2 / 3$ or segment $6 / 7$ resection [38]. Complete segmentectomy can be performed after selective occlusion of the supplying portal branch (while clamping the ipsilateral hepatic artery) using a balloon catheter introduced under ultrasound guidance. The borders of the segment are identified by demarcation of the liver parenchyma or may be enhanced by injecting mythelene blue into the portal branch after occlusion [39]. The extra-glissonian, posterior approach as described by Launois [40] also allows isolation of one or two segments. Using this technique, the segmental pedicles to the liver segments to be resected are dissected in the liver hilum, without opening of the glissonian sheath. Clamping of the segmental pedicle leads to demarcation of the liver parenchyma according to the segmental borders. This parenchymasparing approach is particularly useful when performing central liver resections or resection of segments $5 / 8$. 


\section{Total Hepatic Vascular Exclusion}

When backflow from the hepatic veins still causes major blood loss during vascular inflow occlusion, total hepatic vascular exclusion (THVE) can be applied, in which the supra- and infrahepatic caval vein are clamped in addition to the portal vein and hepatic artery [41]. The infrahepatic caval vein is clamped above the renal veins and right adrenal vein. Also, when the tumor is infiltrating the IVC or caval-hepatic junction, THVE may be used to resect the tumor along with part of the caval vein. THVE is associated with hemodynamic intolerance in 10-20\% of patients because of the reduction in venous return and hence, cardiac output. Application of THVE therefore requires close hemodynamic monitoring of the patient and anesthetic expertise. However, even in the presence of adequate surgical and anesthetic expertise, increased morbidity and hospital stay in patients undergoing THVE have been reported [42].

THVE enables application of in situ hypothermic perfusion of the liver, as was already described by Fortner [43] in 1974. With this technique, the liver is cooled during ischemia via hepatic arterial or portal venous perfusion with a cold solution [44]. Cooling of the liver results in decreased oxygen and energy demand due to a lower rate of metabolism. Cellular metabolism is reduced twofold when temperature is lowered by $10^{\circ} \mathrm{C}[45,46]$. Hypothermic perfusion can only be applied during THVE and not during Pringle's maneuver alone, because during total vascular exclusion, hepatic venous drainage is blocked, preventing perfusion solution to flow via the caval vein into the systemic circulation. Hypothermic perfusion has been shown to be effective in experimental as well as in clinical studies [47-49].

To avoid the hemodynamic complications of THVE, selective extraparenchymal occlusion of the major hepatic veins has been proposed in combination with vascular inflow occlusion (selective hepatic vascular occlusion, SHVE) [50-52]. For this alternative to be effective, the right hemi-liver needs to be mobilized and all short hepatic veins taken down first. SHVE has been shown to be equally effective as THVE in control of blood loss, but SHVE was better tolerated leading to fewer complications and shorter hospital stay [51].

The ultimate condition of liver ischemia is the situation in which the liver is flushed with cold preservation solution and removed completely for an 'ex vivo bench resection', after which the remnant liver is reimplanted [53]. Alternatively, only the suprahepatic caval vein is cut allowing the liver to be reflected anteriorly while leaving the structures in the hepatoduodenal ligament intact. This method is referred to as the ante situm resection as opposed to the extracorporeal, ex situ resection. Obviously, the former method is more complex than the latter, and is only indicated for large tumors involving the caval vein [54].

\section{Discussion}

Control of blood loss, without doubt, is the first requirement for performing safe liver resection and vascular occlusive techniques are well established to limit intraoperative bleeding. The first question that arises, however, is whether we really need the Pringle maneuver or any of its modifications to achieve this goal. Capussotti et al. [55] showed in a randomized clinical trial comparing resection with or without intermittent Pringle maneuver no difference in blood loss or in outcome. The reported blood loss in both groups was 184 and $204 \mathrm{ml}$, respectively, on a per case basis, while the overall mortality was $1.6 \%$. Clearly, these results can only be equaled by a highly experienced team in liver surgery, and may not reflect the average performance in liver surgery. The 'on demand' use of vascular occlusion therefore should be part of any surgical strategy and the surgeon should be familiar with the current methods to control bleeding during liver resection.

Vascular inflow occlusion obviously leads to liver ischemia followed by reperfusion injury when blood flow to the liver is restored. When the ischemic period is prolonged, the impact of reperfusion is greater, hence, it is the combination of ischemic damage per se, and the ensuing reperfusion injury that ultimately determines the damage inflicted to the liver. It is uncertain what the limits of ischemia are in the normal human liver. Several studies have shown that the liver tolerates periods of normothermic ischemia up to $90-120 \mathrm{~min}$, in normal livers as well as in cirrhotic livers [41, 56-58]. Although the human liver might tolerate ischemia better than excessive blood loss, the adverse effects of ischemia should not be disregarded. The damage incurred by post-ischemic reperfusion to the liver parenchymal cells and the microvascular system are well established, both in experimental studies as well as in clinical studies [26, 49, $59,60]$. Especially in livers with pre-existent disease such as cirrhosis or steatosis, the injurious effects of ischemia/reperfusion injury have shown to be enhanced [61]. Post-resectional regeneration of the remnant liver has also been shown to be delayed after vascular inflow 
occlusion in an experimental model of cirrhosis in the rat [62].

Another interesting aspect is the biological effect of tissue injury on the outgrowth of tumor in the remnant liver. There are experimental data showing that vascular inflow occlusion accelerates local outgrowth of pre-established tumor liver metastases in mice. This phenomenon has been associated with the inflammatory response secondary to local tissue damage induced by ischemia and subsequent reperfusion $[63,64]$. In view of these considerations, it seems advisable not to clamp the hepatic pedicle as a routine during liver resection, but to reserve this maneuver when bleeding needs to be curbed, hence, when blood loss is more than desired.

\section{Concluding Remarks}

To clamp or not to clamp is a matter of choice, and is dictated by the need to reduce blood loss during parenchymal transection. The repertoire of liver surgeons should contain the regular clamping methods to reduce blood loss during complex liver resection or to prevent massive blood loss in case of accidental injury to major vessels during mobilization of the liver. Therefore, especially in the setting of a training program in hepatic sur- gery, it is important to prepare for clamping even when vascular occlusion is not used during the procedure. In our unit, maintenance of low CVP $\left(<5 \mathrm{~cm} \mathrm{H}_{2} \mathrm{O}\right)$ is prerequisite for performing a safe liver resection and the anesthetic team is aware of the impact of CVP on outcome of the operation. Encircling the hepatoduodenal ligament, mobilization of the caval vein, division of all short hepatic veins, and control of the supra- and infrahepatic caval vein cranial to the renal veins should be the first steps in any major liver resection. The decision to apply one of the methods of vascular occlusion is, in our unit, made on an individual basis and depends on the extent or complexity of the resection and the quality of the liver parenchyma. In a case of a straightforward, anatomical resection such as in right hemihepatectomy, in which parenchymal transection can be completed within $45 \mathrm{~min}$, the continuous Pringle maneuver is applied when deemed necessary to limit blood loss. In case of more complex resections or when there is pre-existing parenchymal disease, intermittent clamping is the preferred method. THVE is nowadays mostly used for resection of tumors involving the IVC or caval-hepatic junction. Alternatively, extraparenchymal control of the major hepatic veins can be achieved in combination with inflow occlusion, thus preserving caval flow.

\section{References}

1 Jarnagin WR, Gonen M, Fong Y, DeMatteo RP, Ben Porat L, Little S, Corvera C, Weber S, Blumgart LH: Improvement in perioperative outcome after hepatic resection: analysis of 1,803 consecutive cases over the past decade. Ann Surg 2002;236:397-406.

$\checkmark 2$ Couinaud C: Liver anatomy: portal (and (suprahepatic) or biliary segmentation. Dig Surg 1999;16:459-467.

3 DeMatteo RP, Fong Y, Jarnagin WR, Blumgart LH: Recent advances in hepatic resection. Semin Surg Oncol 2000;19:200207.

-4 Abdalla EK, Noun R, Belghiti J: Hepatic vascular occlusion: which technique? Surg Clin N Am 2004;84:563-585.

5 Smyrniotis V, Farantos C, Kostopanagiotou G, Arkadopoulos N: Vascular control during hepatectomy: review of methods and results. World J Surg 2005;29:1384-1396.

6 Jones RMCL, Moulton CE, Hardy KJ: Central venous pressure and its effect on blood loss during liver resection. Br J Surg 1998;85: 1058-1060.
7 Melendeze JA, Arslan V, Fischer ME, et al: Perioperative outcomes of major hepatic resections under low central venous pressure anaesthesia: blood loss, blood transfusion, and the risk of preoperative renal dysfunction. J Am Coll Surg 1998;187:620-625.

8 Pringle JH: Note on the arrest of hepatic hemorrhage due to trauma. Ann Surg 1908; 48:541-549.

9 Grace PA, Mathie RT: Ischemia-Reperfusion Injury. Oxford, Blackwell Science, 1999.

10 Jaeschke H: Mechanisms of reperfusion injury after warm ischemia of the liver. J Hepatobiliary Pancreat Surg 1998;5:402-408.

11 Teoh NC, Farrell GC: Hepatic ischemia reperfusion injury: pathogenic mechanisms and basis for hepatoprotection. J Gastroenterol Hepatol 2003; 18:891-902.

12 Veen SQ van, Dinant S, Vliet AK van, van Gulik TM: Alkaline phosphatase reduces hepatic and pulmonary injury in liver ischaemia/reperfusion combined with partial resection Br J Surg 2006;93:448-456.
13 Van Gulik TM, Heijnen BHM: Experimental liver resection; in Kockerling F, Schwartz SI (eds): Liver Surgery. Operative Techniques and Avoidance of Complications. Heidelberg, Barth, 2001.

14 Schauer RJ, Gerbes AL, Vonier D, Meissner H, Michl P, Leiderer R, Schildberg FW, Messmer K, Bilzer M: Glutathione protects the rat liver against reperfusion injury after prolonged warm ischemia. Ann Surg 2004;239: 220-231.

15 Zhou T, Chen JL, Song W, Wang F, Zhang MJ, Ni PH, Geng JG: Effect of $N$-desulfated heparin on hepatic/renal ischemia reperfusion injury in rats. World J Gastroenterol 2002;8:897-900.

16 El Gibaly AM, Scheuer C, Menger MD, Vollmar B: Improvement of rat liver graft quality by pifithrin- $\alpha$-mediated inhibition of hepatocyte necrapoptosis. Hepatology 2004;39: 1553-1562.

- 17 Maksan SM, Maksan MO, Gebhard MM, Herfarth C, Klar E: Reduction of hepatic reperfusion injury by antithrombin III and aprotinin. Transpl Int 2000;13(suppl 1): S562-S564. 
18 Meguro M, Katsuramaki T, Kimura H, Isobe M, Nagayama M, Kukita K, Nui A, Hirata K: Apoptosis and necrosis after warm ischemia-reperfusion injury of the pig liver and their inhibition by ONO-1714. Transplantation 2003;75:703-710.

$\checkmark 19$ Heijnen BHM, Straatsburg IH, Padilla ND, Mierlo GJ van, Hack CE, van Gulik TM: Inhibition of classical complement activation attenuates liver ischaemia and reperfusion injury in a rat model. Clin Exp Immunol 2006;143:15-23.

20 Dinant S, Veteläinen RL, Florquin S, van Vliet AK, Van Gulik TM: Interleukin-10 attenuates inflammation and apoptosis and promotes hepatocyte proliferation in hepatic ischemia/reperfusion injury. J Surg Res 2007; in press.

-21 Dominguez Fernandez E, Flohe S, Siemers F, Nau M, Ackermann M, Ruwe M, Schade FU: Endotoxin tolerance protects against local hepatic ischemia/reperfusion injury in the rat. J Endotoxin Res 2000;6:321-328.

22 Colletti LM, Green M: Lung and liver injury following hepatic ischemia/reperfusion in the rat is increased by exogenous lipopolysaccharide which also increases hepatic TNF production in vivo and in vitro. Shock 2001; 16:312-319.

23 Filos KS, Kirkilesis I, Spiliopoulou I, Scopa CD, Nikolopoulou V, Kouraklis G, Vagianos CE: Bacterial translocation, endotoxaemia and apoptosis following Pringle manoeuvre in rats. Injury 2004;35:35-43.

-24 Lemaire LC, van Wagensveld BA, van Gulik TM, Dankert J, van Lanschot JJ, Gouma DJ: Bacterial translocation to the thoracic duct in a setting of ischemia, partial resection and reperfusion of the porcine liver. Dig Surg 1999; 16:222-228.

- 25 Peralta C, Hotter G, Closa D, Gelpí E, Bulbena O, Rosello-Catafau J: Protective effect of preconditioning on the injury associated to hepatic ischemia-reperfusion in the rat: role of nitric oxide and adenosine. Hepatology 1997;25:934-937.

26 Clavien PA, Selzner M, Rüdiger HA, et al: A prospective study in 100 consecutive patients undergoing major liver resection with versus without ischemic preconditioning. Ann Surg 2003;238:843-852.

27 Belghiti J, Noun R, Malafosse R, Jagot P, Sauvenet S, Pierangeli F, Marty J, Farges O: Continuous versus intermittent portal triad clamping for liver resection: a controlled study. Ann Surg 1999;229:369-375.

28 Hardy KJ, Tancheroen S, Shulkes A: Comparison of continuous versus intermittent ischaemia-reperfusion during liver resection in an experimental model. Br J Surg 1995;82:833-836

29 Isozaki H, Adam R, Gigou M, Szekely AM, Shen M, Bismuth H: Experimental study of the protective effect of intermittent hepatic pedicle clamping in the rat. Br J Surg 1992; 79:310-313
30 Isozaki H, Okajima K, Kobayashi M, Hara H, Akimoto H: Experimental study of liver injury after partial hepatectomy with intermittent or continuous hepatic vascular occlusion. Differences in tolerance to ischemia between normal and cirrhotic livers. Eur Surg Res 1995;27:313-322.

31 Hewitt G, Halliday I, McCaigue M, Campbell G, Rowlands B, Diamond T: Mortality, endotoxaemia and cytokine expression after intermittent and continuous hepatic ischaemia. Br J Surg 1995;82:1424-1426.

32 Usami M, Furuchi K, Shiroiwa H, Saitoh Y: Effect of repeated portal-triad cross-clamping during partial hepatectomy on hepatic regeneration in normal and cirrhotic rats. J Surg Res 1994;57:541-548.

-33 Van Wagensveld BA, Van Gulik TM, Gabeler EEE, Van der Kleij AJ, Obertop H, Gouma DJ: Intrahepatic tissue $\mathrm{PO}_{2}$ during continuous or intermittent vascular inflow occlusion in a pig liver resection model. Eur Surg Res 1998;30:13-25.

34 Van Wagensveld BA, Van Gulik TM, Gelderblom HC, Scheepers JJG, Bosma A, Endert E, Gouma DJ: Prolonged continuous or intermittent vascular inflow occlusion during hemihepatectomy in pigs. Ann Surg 1999;3: 376-384.

35 Esaki M, Sano T, Shimada K, Sakamoto Y, Takahashi Y, Wakai K, Kosuge T: Randomized clinical trial of hepatectomy using intermittent pedicle occlusion with ischaemic intervals of 15 versus 30 min. Br J Surg 2006; 93:944-951.

36 Wu CC, Hwang CR, Liu TL, Peng FK: Effects and limitations of prolonged ischaemia for hepatic resection of the cirrhotic liver. $\mathrm{Br} \mathrm{J}$ Surg 1996;83:121-124.

37 Takayama T, Makuuchi M, Inoue K, Sakamoto Y, Kubota K, Harihara Y: Selective and unselective clamping in cirrhotic liver. Hepatogastroenterology 1998;45:376-380.

38 Horgan PG, Leen E: A simple technique for vascular control during hepatectomy; the half-Pringle. Am J Surg 2001;182:265-267.

39 Castaing D, Garden OJ, Bismuth H: Segmental liver resection using ultrasound-guided selective portal venous occlusion. Ann Surg 1989;210:20-23.

40 Launois B: Hepatectomy: the posterior intrahepatic approach. Br J Surg 1997;84:291292.

41 Huguet C, Gavelli A, Chieco PA, Bona S, Harb J, Joseph JM, Jobard J, Gramaglia M, Lasserre M: Liver ischemia for hepatic resection: Where is the limit? Surgery 1992;111: 251-259.

42 Belghiti J, Noun R, Zante E, Ballet T, Sauvanet A: Portal triad clamping or hepatic vascular exclusion for major liver resection: a controlled study. Ann Surg 1996;224:155161.
43 Fortner JG, Shiu MH, Kinne DW, Kim DK, Castro EB, Watson RC, Howland WS, Beattie EJ Jr: Major hepatic resection using vascular isolation and hypothermic perfusion. Ann Surg 1974;180:644-652.

44 Hannoun L, Delriviere L, Gibbs P, Borie D, Vaillant JC, Delva E: Major extended hepatic resections in diseased livers using hypothermic protection: preliminary results from the first 12 patients treated with this new technique. J Am Coll Surg 1996;183:597-605.

45 Khandoga A, Enders G, Luchting B, Axmann S, Minor T, Nilsson U, Biberthaler $\mathrm{P}$, Krombach F: Impact of intraischemic temperature on oxidative stress during hepatic reperfusion. Free Radic Biol Med 2003;35: 901-909.

-46 Nagano K, Gelman S, Bradley EL Jr, Parks D: Hypothermia, hepatic oxygen supply-demand, and ischemia-reperfusion injury in pigs. Am J Physiol 1990;258:G910-G918.

47 Azoulay D, Eshkenazy R, Andreani P, Castaing D, Adam R, Ichai P, Naili S, Vinet E, Saliba F, Lemoine A, Gillon MC, Bismuth H: In situ hypothermic perfusion of the liver versus standard total vascular exclusion for complex liver resection. Ann Surg 2005;241: 277-285.

48 Vaillant JC, Borie DC, Hannoun L: Hepatectomy with hypothermic perfusion of the liver. Hepatogastroenterology 1998;45:381388

49 Heijnen BH, Straatsburg IH, Gouma DJ, van Gulik TM: Decrease in core liver temperature with $10^{\circ} \mathrm{C}$ by in situ hypothermic perfusion under total hepatic vascular exclusion reduces liver ischemia and reperfusion injury during partial hepatectomy in pigs. Surgery 2003;134:806-817.

50 Cherqui D, Malassagne B, Colau PI, Brunetti F, Rotman N, Fagniez PL: Hepatic vascular exclusion with preservation of the caval flow for liver resections. Ann Surg 1999;230:2430.

51 Smyrniotis VE, Kostopanagiotou GG, Gamaletsos EL, Vassiliou JG, Voros DC, Fotopoulos AC, Contis JC: Total versus selective hepatic vascular exclusion in major liver resections. Am J Surg 2002;183:173-178.

52 Smyrniotis VE, Kostopanagiotou GG, Contis JC, Farantos CI, Voros DC, Kannas DC, Koskinas JS: Selective hepatic vascular exclusion versus Pringle maneuver in major liver resections: prospective study. World J Surg 2003;27:765-769.

53 Lodge JP, Ammori BJ, Prasad KR, Bellamy MC: Ex vivo and in situ resection of inferior vena cava with hepatectomy for colorectal metastases. Ann Surg 2000;231:471-479.

54 Oldhafer KJ, Lang H, Malago M, Testa G, Broelsch CE: Ex situ resection and resection of the in situ perfused liver: Are there still indications? Chirurg 2001;72:131-137. 
55 Capussotti L, Muratore A, Ferrero A, Massucco P, Ribero D, Polastri R: Randomized clinical trial of liver resection with and without hepatic pedicle clamping. Br J Surg 2006; 93:685-689.

56 Delva E, Camus Y, Nordlinger B, Hannoun L, Parc R, Deriaz H, Lienhart A, Huguet C: Vascular occlusions for liver resections: operative management and tolerance to hepatic ischemia: 142 cases. Ann Surg 1989;209:211218

57 Midorikawa Y, Kubota K, Takayama T, Toyoda H, Ijichi M, Torzilli G, Mori M, Makuuchi M: A comparative study of postoperative complications after hepatectomy in patients with and without chronic liver disease. Surgery 1999;126:484-491.
58 Hannoun L, Borie D, Delva E, Jones D, Vaillant JC, Nordlinger B, Parc R: Liver resection with normothermic ischaemia exceeding one hour. Br J Surg 1993;80:1161-1165.

59 Dinant S, van Veen SQ, Roseboom HJ, van Vliet AK, van Gulik TM: Liver protection by hypothermic perfusion at different temperatures during total vascular exclusion. Liver Int 2006;26:486-493.

60 Menger MD, Richter S, Yamauchi J, Vollmar $\mathrm{B}$ : Role of microcirculation in hepatic ischemia/reperfusion injury. Hepatogastroenterology 1999;46(suppl 2):1452-1457.

61 Vetelainen R, van Vliet A, Gouma DJ, van Gulik TM: Steatosis as a risk factor in liver surgery. Ann Surg 2007;245:20-30.

62 Yin XY, Lai PBS, Lee JFY, Lau WY: Effects of hepatic blood inflow occlusion on liver regeneration following partial hepatectomy in an experimental model of cirrhosis. Br J Surg 2000;87:1510-1515.
63 Van der Bilt JD, Kranenburg O, Nijkamp MW, Smakman N, Veenendaal LM, Te Velde EA, Voest EE, van Diest PJ, Borel Rinkes IH: Ischemia/reperfusion accelerates the outgrowth of hepatic micrometastases in a highly standardized murine model. Hepatology 2005;42:165-175.

64 Van der Bilt JD, Kranenburg O, Verheem A, van Hillegersberg R, Borel Rinkes ICH: Selective portal clamping to minimize hepatic ischaemia-reperfusion damage and avoid accelerated outgrowth of experimental colorectal liver metastases. Br J Surg 2006;93:10151022. 